\section{OPEN ACCESS}

Edited by:

Alicia E. Damiano,

Universidad de Buenos Aires,

Argentina

Reviewed by:

Natalia Szpillbarg,

Instituto de Fisiología y Biofísica

Bernardo Houssay (CONICET),

Argentina

Mariana Farina,

CONICET Centro de Estudios

Farmacológicos y Botánicos (CEFYBO), Argentina

*Correspondence:

Marta Viana

mviana@ceu.es

Specialty section:

This article was submitted to Vascular Physiology,

a section of the journal

Frontiers in Physiology

Received: 11 July 2018

Accepted: 19 October 2018

Published: 06 November 2018

Citation:

Alcala M, Gutierrez-Vega S,

Castro E, Guzman-Gutiérrez E, Ramos-Álvarez MP and Viana M (2018) Antioxidants and Oxidative

Stress: Focus in Obese Pregnancies.

Front. Physiol. 9:1569

doi: 10.3389/fphys.2018.01569

\title{
Antioxidants and Oxidative Stress: Focus in Obese Pregnancies
}

\author{
Martin Alcala',2, Sebastián Gutierrez-Vega ${ }^{2,3}$, Erica Castro 2,4 , \\ Enrique Guzman-Gutiérrez ${ }^{2,3}$, Maria Pilar Ramos-Álvarez ${ }^{1,2}$ and Marta Viana ${ }^{1,2 \star}$
}

${ }^{1}$ Department of Chemistry and Biochemistry, Facultad de Farmacia, CEU San Pablo University - CEU Universities, Madrid, Spain, ${ }^{2}$ Red Iberoamericana de Alteraciones Vasculares Asociadas a TRastornos del EMbarazo (RIVA-TREM), Chillán, Chile, ${ }^{3}$ Molecular Medicine Laboratory, School of Medical Technology, Faculty of Health Sciences, Universidad San Sebastián, Concepción, Chile, ${ }^{4}$ Faculty of Medicine, Universidad San Sebastián, Concepción, Chile

The prevalence of obesity in women of childbearing age around the globe has dramatically increased in the last decades. Obesity is characterized by a low-state chronic inflammation, metabolism impairment and oxidative stress, among other pathological changes. Getting pregnant in this situation involves that gestation will occur in an unhealthy environment, that can potentially jeopardize both maternal and fetal health. In this review, we analyze the role of maternal obesity-induced oxidative stress as a risk factor to develop adverse outcomes during gestation, including reduced fertility, spontaneous abortion, teratogenesis, preeclampsia, and intrauterine growth restriction. Evidences of macromolecule oxidation increase in reactive oxygen species generation and antioxidant defense alterations are commonly described in maternal and fetal tissues. Thus, antioxidant supplementation become an interesting prophylactic and therapeutic tool, that yields positive results in cellular, and animal models. However, the results from most meta-analysis studying the effect of these therapies in complicated gestations in humans are not really encouraging. It is still to be analyzed whether these therapies could work if applied to cohorts of patients at a high risk, such as those with low concentration of antioxidants or obese pregnant women.

Keywords: fertility, preeclampsia, miscarriage, latin-America, teratogenesis, intrauterine growth restriction, oxidative stress

\section{PREVALENCE OF OVERWEIGHT AND OBESITY AMONG WOMEN OF REPRODUCTIVE AGE}

Prevalence of obesity in both developed and developing countries has increased among women over the last decades (Heslehurst et al., 2007; NCD Risk Factor Collaboration, 2016), including the prevalence in women of childbearing age, which has also raised dramatically worldwide (Nguyen et al., 2008; Menting et al., 2018; Schaefer-Graf et al., 2018), from 29.8\% in 1980 to $38.0 \%$ in 2013 (Ng et al., 2014). Correa and Marcinkevage reported an average global prevalence of obesity in women of childbearing age ranging between $1 \%$ in Chad to $70.3 \%$ in Tonga (Correa and Marcinkevage, 2013).

Abbreviations: AGA, appropriate for gestational age; GSH, glutathione; GWG, gestational weight gain; IUGR, intrauterine growth restriction; LGA, large for gestational age; MDA, malondialdehyde; NAC, N-acetylcysteine; OR, odds ratio; OS, oxidative stress; PE, preeclampsia; ROS, reactive oxygen species; SGA, small for gestational age. 
The available epidemiological data in Latin-American countries are dispersed, obtained from periodic national surveys in some cases, or from low-scale, punctual regional studies in others. As it is shown in the Figure 1, the highest prevalence of obesity in women of reproductive age was found in Mexico, while the lowest prevalence was found in Haiti.

The trend in the prevalence of obesity has become a matter of concern to preconception healthcare programs because prepregnancy obesity and excessive GWG is associated with an increased risk of adverse reproductive health outcomes (Dolin and Kominiarek, 2018; Most et al., 2018). Obesity reduces fertility and increases time taken to conceive (Poston et al., 2016). At the beginning of the gestation, obese pregnant women are more likely to have spontaneous and recurrent pregnancy loss (Chu et al., 2007). The rate of embryo malformations is also increased, showing mainly neural tube, and cardiac defects (Rasmussen et al., 2008). During mid-late gestation, obesity pregnancies have an increased risk for PE and gestational diabetes mellitus, both of which are associated with long-term morbidities post-partum (Milne et al., 2009; Poston et al., 2016). Obese women can also experience difficulties during labor and delivery. The chances of requiring a cesarean intervention in obese mothers double that of lean mothers, while the comorbidity (anesthetic complications, massive blood loss) reaches almost $34 \%$ of the gestations. For the newborn, there is a higher risk of LGA, macrosomia, shoulder dystocia and even obesity in childhood (Dennedy and Dunne, 2010; Nelson et al., 2010; Most et al., 2018).

Obesity is associated with a dysregulation in the metabolic balance comprising lipid metabolism, inflammatory or hormonal processes in addition to insulin resistance (Bozkurt et al., 2016). The pathogenesis of obesity is complex and includes metabolic and hormonal dysregulation, low-grade chronic inflammation and endoplasmic reticulum stress, among other processes that are closely interconnected. Several groups all over the world, including ourselves (Alcala et al., 2015), have focused our research in the role of oxidative stress as a central mechanism that may enhance the aforementioned conditions. In this context, we have shown how the use of antioxidants in long-term obesity reduces obesity-associated inflammation, insulin resistance and tissue fibrosis. In the following lines we will discuss the role of OS before, during and after gestation in the mother with pregestational obesity and in the offspring, reviewing the use of antioxidant therapies to ameliorate or prevent undesired negative outcomes.

\section{OXIDATIVE STRESS}

OS has been traditionally recognized as a key factor in the pathophysiology of numerous conditions, including cardiovascular and neurodegenerative diseases, cancer, diabetes, and obesity.

OS has been classically defined as an imbalance between ROS generation and its detoxification by antioxidant systems, in favor of the former. ROS are partially reduced, oxygen-containing metabolites (some of them are free radicals) that are generated because of normal cellular metabolism and environmental factors. They are extremely reactive and have the potential to oxidize lipids, proteins and DNA. On the other side, enzymatic (superoxide dismutase, catalase, glutathione peroxidase) and non-enzymatic (vitamin $\mathrm{C}$ and $\mathrm{E}$, glutathione) antioxidants neutralize the effect of highly reactive ROS by transforming them into less reactive species and eliminating oxidation by-products, protecting cells from oxidative damage.

However, ROS, at a physiological concentration, behave as second messengers in several signaling pathways that are critical for the normal cellular function. Several studies in the last 10 years have described how ROS can modify the redox state of key residues of proteins (Jones et al., 2004) regulating enzyme activity. They have been reported to participate in different signaling pathways (NF-кB, PTP1b, ASK1, PTEN, REF1, p66hc, or IRP1) (Ray et al., 2012).

Adipose tissue has been proposed as the origin of obesityinduced OS, that is later transmitted to other tissues and may account for obesity-associated diseases such as hypertension, cardiovascular disease, or even cancer (Furukawa et al., 2004; Matsuda and Shimomura, 2013). Hyperglycemia, hyperleptinemia, endothelial dysfunction, hyperlipidemia and mitochondrial dysfunction are the main mechanisms that have been described to increase ROS-generation systems such as nitric oxide synthases (NOS) or NADPH oxidases (Savini et al., 2013). In the first stages of obesity, an upregulation of the antioxidant enzymes is observed to prevent oxidative damage, but as fat accumulates the antioxidant defense is overtaken, leading to OS (Alcala et al., 2015; Alcala et al., 2017).

In addition, oxidative stress has also been observed in healthy gestation. In the second trimester, there is a spike in oxygen supply and metabolic rate in placenta. If ROS levels are maintained under control, they regulate trophoblast proliferation, invasion and angiogenesis, required for a healthy pregnancy (Wu et al., 2015).

Thus, both obesity and gestation are characterized by an increased OS. When combined, OS is one of the proposed mechanisms involved in many reproductive and pregnancy disorders that may lead to adverse pregnancy outcomes (Malti et al., 2014).

\section{OXIDATIVE STRESS, MATERNAL OBESITY AND PREGNANCY OUTCOMES}

\section{Fertility}

Pre-existing obesity is an independent risk factor for anovulation, subfertility and infertility in women (Silvestris et al., 2018). Several studies show a positive correlation between maternal BMI and time-to-pregnancy (Gesink Law et al., 2007; Wise et al., 2010). It is estimated that for every unit of increase in the BMI, there is a $5 \%$ decrease in the probability of conception (van der Steeg et al., 2008). On the other hand, weight loss strategies may positively influence in fertility (Sim et al., 2014). A 10\% of weight loss in overweight patients with infertility significantly improved conception and live birth rates (Kort et al., 2014).

The deleterious effect of obesity on reproduction is mainly driven by endocrine and metabolic alterations, which may 


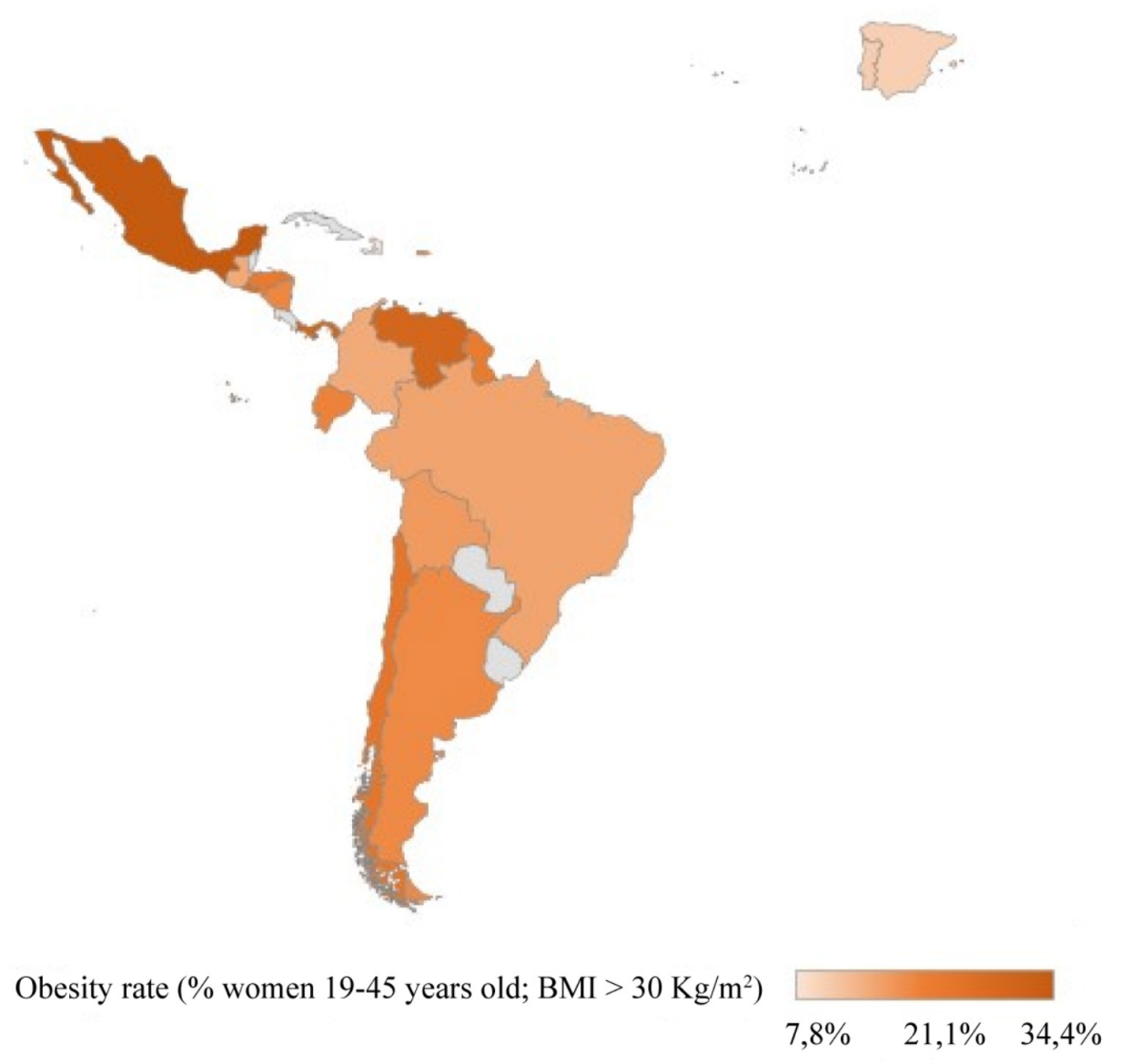

FIGURE 1 | Estimates of obesity in women of childbearing age in Latin-America. Percentage of obesity $\left(\mathrm{BMl} \geq 30 \mathrm{Kg} / \mathrm{m}^{2}\right)$ in women between 18 and 45 years old. BOL, BRA, COL, ECU, ESV, GUA, HAI, HON, MEX, NIC, PER, and GUY obesity prevalence obtained from National Health Surveys and compilated in (Correa and Marcinkevage, 2013). VEN prevalence obtained from Instituto Nacional de Nutrición (2008-2010). CHI obesity prevalence obtained from Encuesta Nacional de Salud (ENS-2009) and reviewed in (Araya et al., 2014). PAN obesity prevalence obtained from cross-sectional studies (2010-2011) (Mc Donald et al., 2015). ARG obesity prevalence obtained from Encuesta Nacional de Nutrición y Salud (ENNyS-2007). PR obesity prevalence obtained from self-reported, prospective longitudinal cohort study (2011-2014) (Guilloty et al., 2015). SPA and POR obesity prevalence obtained from the European Health Interview Survey (EHIS 2014).

interfere with the neuroendocrine and ovarian function through a disruption in the hypothalamus-hypophysis-ovarian axis. The mechanisms underlying the defective endocrine program in obese women include metabolic alterations due to hyperinsulinemia, the effect of pro-inflammatory cytokines, endoplasmic reticulum stress, alterations in the mitochondria and OS (Silvestris et al., 2018).

In rodents, oocytes from dams fed on high fat diet showed abnormal mitochondrial morphology and increased activity, resulting in increased ROS production and GSH reduction (Igosheva et al., 2010) leading to meiosis failure (Han et al., 2017; Wang et al., 2018). Circulating markers of OS are also elevated in women with polycystic ovary syndrome, with a remarkable $50 \%$ decline in GSH concentration. In fact, GSH seems to be a critical player in both male and female fertility. The lack of the enzyme that catalyzes the rate-limiting step in GSH synthesis, the glutamate cysteine ligase, in female mice dramatically reduced preimplantation development (Nakamura et al., 2011; Lim et al., 2015).
The use of antioxidants to improve fertility in obese patients is still a matter of debate. A recent meta-analysis concludes that there is low-quality evidence of a beneficial effect of antioxidants to increase fertility (Showell et al., 2017). However, this report fails to independently analyze a cohort of women with pregestational obesity, where the oxidative insult may arise from the combination of two situations that are, independently, associated to oxidative stress. In this situation, the use of antioxidants such as resveratrol in preclinical studies using rodent models (Ghowsi et al., 2018; Jia et al., 2018), or in randomized control trials in humans using Mg and Zn (Afshar Ebrahimi et al., 2017) or NAC (Nasr, 2010; Maged et al., 2015) improved overall reproductive outcome.

\section{Miscarriage and Obesity}

Overweight and obese pregnant women present a higher risk of pregnancy loss and recurrent miscarriage compared to normal weight gestations (OR vary from 1.31 to 1.67 ) (Metwally et al., 2008; Boots and Stephenson, 2011). There is an even higher risk 
for obese women of recurrent early miscarriage in spontaneous conception (OR: R: 3.51; 95\% CI, 1.03-12.01) and miscarriage after ovulation induction (OR: 5.11; 95\% CI, 1.76-14.83).

Recent results suggest a reduced regenerative capacity and plasticity of the endometrium in obese pregnant women (Murakami et al., 2013), factors that may predispose for pregnancy loss (Lucas et al., 2016).

Another key step for a successful pregnancy is a proper maternal-fetal exchange. From week 8 to 12 of gestation there is a peak in placental $\mathrm{pO}_{2}$ when the maternal blood enters the placenta. This signal triggers the transcription of antioxidant genes (catalase, glutathione peroxidase, and superoxide dismutase) to overcome the prooxidant environment (Jauniaux et al., 2000). In obese pregnancies, together with a pre-established oxidative situation (Catalano and Shankar, 2017), there is a dysregulation of immune cells within the endometrium, characterized by a reduced presence of the antiinflammatory Treg lymphocytes and an increase of natural killer lymphocytes (Quenby et al., 2009). This promotes early angiogenesis, increasing placental $\mathrm{pO}_{2}$ prior to the establishment of a mature antioxidant system, depleting non-enzymatic antioxidants such as GSH and vitamin E (Hansen and Harris, 2013). Several authors have described an increase in OS markers in placenta from early and recurring pregnancy loss and suggested that increased ROS generation may be caused by premature establishment of maternal placental perfusion, which has been correlated with a higher risk of miscarriage (Miller et al., 2000; Burton and Jauniaux, 2004; Yiyenoglu et al., 2014).

However, current meta-analyses have shown no beneficial effect of the administration of vitamins (alone or in combination) prior to pregnancy or during the early stages of pregnancy (Balogun et al., 2016). Given the importance of GSH metabolism to fully develop a successful pregnancy, more studies should be carried out to evaluate the potential of NAC (a GSH precursor) to prevent obesity-related miscarriage. So far, the supplementation with NAC to women with recurrent unexplained pregnancy loss significantly increased the rate of living pregnancies beyond 20 weeks and the take-home baby rate (Amin et al., 2008).

\section{Malformation}

Congenital anomalies are the end-products of aberrant organogenesis in utero during the first trimester of gestation. A meta-analysis in 2009 revealed that newborns from obese mothers are at increased risk of severe congenital malformations, including neural tube defects and cardiovascular anomalies (Stothard et al., 2009). Results from a cohort including more than 1.2 million deliveries, showed that liveborn singletons from mothers with a BMI $>40 \mathrm{~kg} / \mathrm{m}^{2}$ almost double the risk of suffering major congenital malformations in the nervous system compared to the offspring of normal weight mothers (Persson et al., 2017).

The mechanisms involved in obesity-mediated teratogenesis are still unrevealed. Traditionally, the fuel-mediated teratogenesis hypothesis claims that exposing the embryo to an excessive amount of nutrients, mainly glucose and ketone bodies, may promote embryo malformations, inappropriate organ development and metabolic disturbances in the youth (Freinkel, 1980; Catalano, 2010; Plagemann and Harder, 2011).

OS, common feature in maternal obesity (Gallardo et al., 2015), has been suggested as a potential mechanism in the teratogenesis induced by diabetes (Viana et al., 1996) or chemical teratogens such alcohol, cocaine, valproate, or thalidomide (Hansen and Harris, 2013).

In addition to a direct effect on DNA damaging and repair (Wells et al., 2010), at a molecular level, OS has been shown to inhibit Pax3 upregulation during early embryogenesis in a murine embryonic stem cell model (Wu et al., 2012). Pax3 is a transcription factor required for neural tube development. As a result, cardiac neural crest and neuroepithelial cells undergo apoptosis by a process dependent on the p53 tumor suppressor protein (Wang et al., 2011). The supplementation with GSH and vitamin $\mathrm{E}$ has proven to be effective in the upregulation of Pax3 expression after an oxidative insult (Wu et al., 2012).

To the best of our knowledge, there is not any clinical trial, to test the potential protective effects of antioxidant supplementation in pre-gestational obese women. However, using retrospective, survey-based studies, a reduction in antioxidant consumption has been linked to increase odds of limb and neural tube defects in obese pregnant women (Chandler et al., 2012; Pace et al., 2018).

\section{Preeclampsia and Cardiovascular Alterations}

$\mathrm{PE}$ is a severe disease characterized by the presence of hypertension and proteinuria during the second and third trimester of gestation (Steegers et al., 2010). PE affects approximately $2-8 \%$ of all pregnancies (Ghosh et al., 2014) and is associated with substantially higher maternal and fetal morbidity and mortality worldwide, especially in Latin American countries where $\mathrm{PE}$ is one of the leading causes of maternal and fetal mortality (Giachini et al., 2017).

PE women exhibit at least a twofold increased risk of stroke, while risk of death due to ischemic heart disease is eight times higher when PE occurs before 34 weeks of gestation (Deanfield et al., 2005). Indeed, the American Heart Association has included PE as a risk factor for future cardiovascular disease (Bushnell et al., 2014).

Obesity has been listed as a major risk factor for PE (Marchi et al., 2015), together with higher waist circumference, blood pressure, insulin, proinsulin, glucose, C-reactive protein and triglycerides levels, and lower HDL cholesterol (MongrawChaffin et al., 2010; Sliwa and Bohm, 2014).

The current well-accepted pathophysiology of PE involves a two-stage model: first, an incomplete remodeling of the spiral arteries communicating maternal and placental blood flow through a defective trophoblast invasion. This leads to the second stage, where the ischemia-reperfusion cycles triggers the release of harmful molecules including ROS, cytokines, antiangiogenic proteins, cell fragments, microparticles, and extracellular vesicles (Redman and Sargent, 2000, 2005; Tannetta et al., 2013; Hod et al., 2015). These elements may reach the maternal circulation and 


\section{Gestational period}

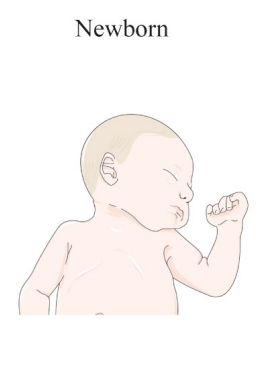

IUGR/SGA

$$
\text { Preconceptional }
$$

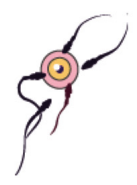$$
\text { Implantation }
$$

Embryo

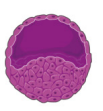

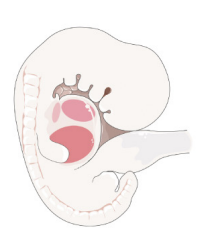

Placental/vascular abnormalities

Malformations

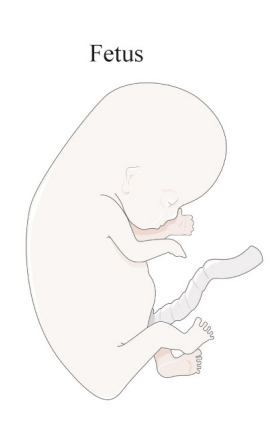

Fertility
Miscarriage

\section{Gestational outcome}

Influence of oxidative stress
DNA damage plasticity

Early placental angiogenesis
Pax3 inhibition in neural crest cells, leading to apoptosis
Defective arterial remodeling

Altered vascular relaxation/contraction capacity
Defective arterial remodeling

Reduced nutrient and $\mathrm{O}_{2}$ supply

\section{Oxidative stress markers}

Increased ROS and MDA, decrease GSH, SOD and GPx activity in oocytes,

Increased ROS before

Vitamin E and GSH depletion antioxidant enzymes are mature. in maternal liver and embryo Vitamin E and GSH depletion

Increased mitochondrial ROS, MDA and isoprostanes in placenta.

Increased xantine oxidase activity.
Increased ROS, MDA and isoprostantes in placenta. Upregulation of SOD and GPx. Vitamin E and GSH depletion

FIGURE 2 | Obesity, gestation and oxidative stress. Pregestational obesity increases the risk of suffering adverse outcomes prior (reduced fertility), during (spontaneous abortion, embryo malformations, preeclampsia, intrauterine growth retardation) and after gestation (small and large for gestational age deliveries) for both the mother and the fetus. Oxidative stress is a common feature in the etiology of obesity and can cause an accumulative effect with the oxidative stress that appears during gestation. The effects and the evidences of oxidative stress in obesity-complicated pregnancies are here summarized. IUGR, intrauterine growth retardation; SGA, small for gestational age; ROS, reactive oxygen species; MDA, malondialdehyde. Artwork was obtained from Servier Medical Art, licensed under a Creative Common Attribution 3.0 Generic License. http://smart.servier.com/.

are thought to be the causative factors of endothelial dysfunction (Roberts and Escudero, 2012).

OS, common in obesity, appears to be the central component of both placental and endothelial dysfunction (Aouache et al., 2018). Pregestational obesity modifies the arterial architecture in placenta (Avagliano et al., 2012) and its contraction/relaxation capacity, being more susceptible to maternal OS (Saker et al., 2008). In addition, obese placenta presents an increased generation of mitochondrial ROS caused by a defective respiratory chain (Hastie and Lappas, 2014), that has been linked to placental angiodysplasia (Ishii et al., 2014). The following episodes of hypoxia/reoxygenation induce the activity of the xanthine oxidase, an important source of superoxide (Hung et al., 2002).

Oxidative damage in the placenta leads to inflammation, apoptosis and the release of cellular debris into maternal circulation, along with several anti-angiogenic factors, cytokines and oxidants (MDA, isoprostanes) concomitant with a reduced antioxidant capacity (Atamer et al., 2005). These placentalderived factors act on the maternal vascular endothelium, inducing more OS and stimulating the production and secretion of pro-inflammatory cytokines, as well as vasoactive compounds. This results in a massive systemic endothelial dysfunction characterized by vascular inflammation and constriction (Goulopoulou and Davidge, 2015).

Preclinical experiments in cellular and animal models reported beneficial effects of antioxidants reducing maternal blood pressure and improving endothelial function (Chang et al., 2005; Roes et al., 2006; McCarthy and Kenny, 2016). However, meta-analysis from clinical trials in humans did not support the use of antioxidant therapy to reduce the risk of PE (Rumbold et al., 2008, 2015; Roberts et al., 2010). It is important to notice that none of these reviews stratify the population according to the $\mathrm{BMI}$, so the effect of antioxidants on PE women with a preexisting oxidative situation has not been studied yet.

\section{Intrauterine Growth Restriction and Obesity}

An adequate transport of $\mathrm{O}_{2}$ and nutrients in the motherplacenta-fetus circuit is mandatory for the normal development of gestation. An excess in the nutrient supply from obese mothers 
(Rosario et al., 2015) has been strongly associated with alterations in fetal growth (Yu et al., 2013), increasing the risk of delivering LGA (Bove et al., 2014). Strikingly, epidemiological studies have also noticed that SGA deliveries are also more frequent among overweight and obese women (Radulescu et al., 2013). It is still to be confirmed whether pregestational BMI or GWG have more impact on fetal growth (Crane et al., 2009). In any case, both pregnancy outcomes, SGA and LGA, have an increased risk of suffering perinatal complications, including stillbirth (Yao et al., 2017) and complications later in life.

LGA newborns are the result of an increased flux of oxygen and nutrients together with placental overgrowth (Gaccioli et al., 2013), with a feature gene expression and more OS than those AGA (Saker et al., 2008). Even several years after delivery, in a prepubertal age, LGA children present more OS and insulin resistance than AGA (Chiavaroli et al., 2009).

On the other hand, IUGR in obesity is partly caused by a defective oxygen and nutrient supply to the placenta, which resembles the pathological basis of PE (Srinivas et al., 2009). However, not every case of IUGR can be explained by preexisting $\mathrm{PE}$, so the presence of divergent molecular mechanisms has been proposed by some authors (Villar et al., 2006).

Nonetheless, OS is present in both conditions and may have a critical impact on the development of the disease. In fact, an increase in oxidative markers (MDA, isoprostanes, protein carbonyls) has been found in placenta, maternal and chord plasma (Longini et al., 2005; Biri et al., 2007; Zadrozna et al., 2009; Mert et al., 2012; Negro et al., 2017) of IUGR-complicated pregnancies, with and without PE. Enzymatic antioxidant defenses are also upregulated, as an increase in superoxide dismutase or glutathione peroxidase activities have been previously described. However, non-enzymatic antioxidants, such as GSH, vitamin E and C contents are depleted (Biri et al., 2007; Rajasingam et al., 2009; Zadrozna et al., 2009; Mert et al., 2012), reflecting an OS situation.

To our knowledge, there is not any published clinical trial in humans to determine the potential effect of antioxidants (vitamins or GSH-precursors) on the intrauterine growth from obese mothers. Retrospective, food intake survey-based studies, showed conflicting results. For example, in Spain no relation was found between the consumption of antioxidant vitamins and SGA frequency (Salcedo-Bellido et al., 2017) and a meta-analysis about the use of vitamin E during pregnancy showed no beneficial effect to prevent poor fetal growth in healthy pregnancies (Cohen et al., 2015; Rumbold et al., 2015).

\section{CONCLUSION}

Pregestational obesity affects approximately to 1 out of 3 women of childbearing age in the world. The excessive fat mass accumulation correlates with OS, caused by an overactivation of the ROS-generating systems (mainly NOS and NADPH oxidases) and a depleted antioxidant defense. Obesity-induced OS arises as a central factor that increases the risk of adverse outcomes in gestation, as it has been summarized in the Figure 2. Prior to gestation, obesity-related OS can cause decreased fertility due to a defective meiosis and mitochondrial alterations in the oocytes. On early gestation, OS increases the risk of miscarriage by reducing the plasticity of the endometrium and promoting early angiogenesis, that increases oxygen supply prior to the maturation of the antioxidant systems. OS can directly cause DNA damage and the inhibition of key genes for neural tube development and closure, responsible for some of the most common malformations observed in embryos from obese mothers. During the second trimester, placenta becomes another physiological source of ROS, with a physiological role on materno-fetal connection. However, the combination of both sources of OS in obese pregnancies can cause an overproduction of ROS, that may account for a defective vascularization of the placenta, leading to both hyperoxia and hypoxia. These two situations exacerbate the placental oxidative state and participate in the pathology of vascular conditions such as PE and IUGR.

Despite the multiple evidence of the oxidative disbalance along normal pregnancies, the use of antioxidants to prevent these outcomes is conflicting. While they have proven to be effective in preclinical studies in cellular and animal models, the reports of its application in large-scale clinical trials is often discouraging. However, the analyzed clinical trials in this mini-review do not specifically analyze a cohort of women with pregestational obesity. The design of specific clinical trials for this population, with a basal situation of increased OS, could potentially generate more promising results. Besides clinical recommendations to obese women, such as weight loss before conception and controlling GWG, specific studies on antioxidant therapies focused on this population could help clarifying the adequacy of targeting OS to prevent complications.

\section{AUTHOR CONTRIBUTIONS}

MA and MV participated in the conception of the work and in the preparation of the manuscript. SG-V, EC, EG-G, and MR-Á participated in the preparation of the manuscript and critically reviewed the final draft.

\section{FUNDING}

This work was supported by the Spanish Ministry of Economy and Competitiveness (SAF2014-56671-R) and Community of Madrid (S2017/BMD-3864) to MR-Á; by the Universidad CEU San Pablo-Banco Santander (FUSP-BS-PPCUSP02/2017) to MA and by National Fund for Scientific and Technological Development, FONDECYT iniciación 11170710 and International Networks for research REDI170287 (CONICYT) to EG-G. 


\section{REFERENCES}

Afshar Ebrahimi, F., Foroozanfard, F., Aghadavod, E., Bahmani, F., and Asemi, Z. (2017). The effects of magnesium and zinc co-supplementation on biomarkers of inflammation and oxidative stress, and gene expression related to inflammation in polycystic ovary syndrome: a randomized controlled clinical trial. Biol. Trace Elem. Res. 184, 300-307. doi: 10.1007/s12011-017-1198-5

Alcala, M., Calderon-Dominguez, M., Serra, D., Herrero, L., Ramos, M. P., and Viana, M. (2017). Short-term vitamin E treatment impairs reactive oxygen species signaling required for adipose tissue expansion, resulting in fatty liver and insulin resistance in obese mice. PLoS One 12:e0186579. doi: 10.1371/ journal.pone.0186579

Alcala, M., Sanchez-Vera, I., Sevillano, J., Herrero, L., Serra, D., Ramos, M. P., et al. (2015). Vitamin E reduces adipose tissue fibrosis, inflammation, and oxidative stress and improves metabolic profile in obesity. Obesity 23, 1598-1606. doi: $10.1002 /$ oby. 21135

Amin, A. F., Shaaban, O. M., and Bediawy, M. A. (2008). N-acetyl cysteine for treatment of recurrent unexplained pregnancy loss. Reprod. Biomed. Online 17, 722-726. doi: 10.1016/S1472-6483(10)60322-7

Aouache, R., Biquard, L., Vaiman, D., and Miralles, F. (2018). Oxidative stress in preeclampsia and placental diseases. Int. J. Mol. Sci. 19:E1496. doi: 10.3390/ ijms 19051496

Araya, B. M., Padilla, O., Garmendia, M. L., Atalah, E., and Uauy, R. (2014). Prevalence of obesity among Chilean women in childbearing ages. Rev. Med. Chil. 142, 1440-1448. doi: 10.4067/S0034-98872014001100011

Atamer, Y., Kocyigit, Y., Yokus, B., Atamer, A., and Erden, A. C. (2005). Lipid peroxidation, antioxidant defense, status of trace metals and leptin levels in preeclampsia. Eur. J. Obstet. Gynecol. Reprod. Biol. 119, 60-66. doi: 10.1016/j. ejogrb.2004.06.033

Avagliano, L., Marconi, A. M., Romagnoli, S., and Bulfamante, G. P. (2012). Abnormal spiral arteries modification in stillbirths: the role of maternal prepregnancy body mass index. J. Matern. Fetal Neonatal Med. 25, 2789-2792. doi: 10.3109/14767058.2012.705395

Balogun, O. O., da Silva Lopes, K., Ota, E., Takemoto, Y., Rumbold, A., et al. (2016). Vitamin supplementation for preventing miscarriage. Cochrane Database Syst. Rev. 6:CD004073. doi: 10.1002/14651858.CD004073.pub4

Biri, A., Bozkurt, N., Turp, A., Kavutcu, M., Himmetoglu, O., and Durak, I. (2007). Role of oxidative stress in intrauterine growth restriction. Gynecol. Obstet. Invest. 64, 187-192. doi: 10.1159/000106488

Boots, C., and Stephenson, M. D. (2011). Does obesity increase the risk of miscarriage in spontaneous conception: a systematic review. Semin. Reprod. Med. 29, 507-513. doi: 10.1055/s-0031-1293204

Bove, I., Campoy, C., Uauy, R., Miranda, T., and Cerruti, F. (2014). Trends in early growth indices in the first 24 months of life in Uruguay over the past decade. J. Health Popul. Nutr. 32, 600-607.

Bozkurt, L., Gobl, C. S., Hormayer, A. T., Luger, A., Pacini, G., and KautzkyWiller, A. (2016). The impact of preconceptional obesity on trajectories of maternal lipids during gestation. Sci. Rep. 6:29971. doi: 10.1038/srep 29971

Burton, G. J., and Jauniaux, E. (2004). Placental oxidative stress: from miscarriage to preeclampsia. J. Soc. Gynecol. Investig. 11, 342-352. doi: 10.1016/j.jsgi.2004. 03.003

Bushnell, C., McCullough, L. D., Awad, I. A., Chireau, M. V., Fedder, W. N., Furie, K. L., et al. (2014). Guidelines for the prevention of stroke in women: a statement for healthcare professionals from the American Heart Association/American Stroke Association. Stroke 45, 1545-1588. doi: 10.1161/ 01.str.0000442009.06663.48

Catalano, P. M. (2010). Obesity, insulin resistance, and pregnancy outcome. Reproduction 140, 365-371. doi: 10.1530/REP-10-0088

Catalano, P. M., and Shankar, K. (2017). Obesity and pregnancy: mechanisms of short term and long term adverse consequences for mother and child. BMJ 356:j1. doi: 10.1136/bmj.j1

Cohen, J. M., Beddaoui, M., Kramer, M. S., Platt, R. W., Basso, O., and Kahn, S. R. (2015). Maternal antioxidant levels in pregnancy and risk of Preeclampsia and small for gestational age birth: a systematic review and meta-analysis. PLoS One 10:e0135192. doi: 10.1371/journal.pone.0135192

Correa, A., and Marcinkevage, J. (2013). Prepregnancy obesity and the risk of birth defects: an update. Nutr. Rev. 71(Suppl. 1), S68-S77. doi: 10.1111/nure.12058
Crane, J. M., White, J., Murphy, P., Burrage, L., and Hutchens, D. (2009). The effect of gestational weight gain by body mass index on maternal and neonatal outcomes. J. Obstet. Gynaecol. Can. 31, 28-35. doi: 10.1016/S1701-2163(16) 34050-6

Chandler, A. L., Hobbs, C. A., Mosley, B. S., Berry, R. J., Canfield, M. A., Qi, Y. P., et al. (2012). Neural tube defects and maternal intake of micronutrients related to one-carbon metabolism or antioxidant activity. Birth Defects Res. A Clin. Mol. Teratol. 94, 864-874. doi: 10.1002/bdra. 23068

Chang, E. Y., Barbosa, E., Paintlia, M. K., Singh, A., and Singh, I. (2005). The use of $\mathrm{N}$-acetylcysteine for the prevention of hypertension in the reduced uterine perfusion pressure model for preeclampsia in sprague-dawley rats. Am. J. Obstet. Gynecol. 193(3 Pt 2), 952-956. doi: 10.1016/j.ajog.2005. 05.083

Chiavaroli, V., Giannini, C., D'Adamo, E., de Giorgis, T., Chiarelli, F., and Mohn, A. (2009). Insulin resistance and oxidative stress in children born small and large for gestational age. Pediatrics 124, 695-702. doi: 10.1542/peds.20083056

Chu, S. Y., Kim, S. Y., Lau, J., Schmid, C. H., Dietz, P. M., Callaghan, W. M., et al. (2007). Maternal obesity and risk of stillbirth: a metaanalysis. Am. J. Obstet. Gynecol. 197, 223-228. doi: 10.1016/j.ajog.2007.03.027

Deanfield, J., Donald, A., Ferri, C., Giannattasio, C., Halcox, J., Halligan, S., et al. (2005). Endothelial function and dysfunction. Part I: methodological issues for assessment in the different vascular beds: a statement by the working group on endothelin and endothelial factors of the european society of hypertension. J. Hypertens. 23, 7-17. doi: 10.1097/00004872-20050100000004

Dennedy, M. C., and Dunne, F. (2010). The maternal and fetal impacts of obesity and gestational diabetes on pregnancy outcome. Best Pract. Res. Clin. Endocrinol. Metab. 24, 573-589. doi: 10.1016/j.beem.2010.06.001

Dolin, C. D., and Kominiarek, M. A. (2018). Pregnancy in women with obesity. Obstet. Gynecol. Clin. North Am. 45, 217-232. doi: 10.1016/j.ogc.2018.01.005

Freinkel, N. (1980). Banting lecture 1980. Of pregnancy and progeny. Diabetes 29, 1023-1035. doi: 10.2337/diab.29.12 1023

Furukawa, S., Fujita, T., Shimabukuro, M., Iwaki, M., Yamada, Y., Nakajima, Y., et al. (2004). Increased oxidative stress in obesity and its impact on metabolic syndrome. J. Clin. Invest. 114, 1752-1761. doi: 10.1172/JCI21625

Gaccioli, F., Lager, S., Powell, T. L., and Jansson, T. (2013). Placental transport in response to altered maternal nutrition. J. Dev. Orig. Health Dis. 4, 101-115. doi: $10.1017 /$ S2040174412000529

Gallardo, J. M., Gomez-Lopez, J., Medina-Bravo, P., Juarez-Sanchez, F., ContrerasRamos, A., Galicia-Esquivel, M., et al. (2015). Maternal obesity increases oxidative stress in the newborn. Obesity 23, 1650-1654. doi: 10.1002/oby. 21159

Gesink Law, D. C., Maclehose, R. F., and Longnecker, M. P. (2007). Obesity and time to pregnancy. Hum. Reprod. 22, 414-420. doi: 10.1093/humrep/ del400

Ghosh, G., Grewal, J., Mannisto, T., Mendola, P., Chen, Z., Xie, Y., et al. (2014). Racial/ethnic differences in pregnancy-related hypertensive disease in nulliparous women. Ethn. Dis. 24, 283-289.

Ghowsi, M., Khazali, H., and Sisakhtnezhad, S. (2018). The effect of resveratrol on oxidative stress in the liver and serum of a rat model of polycystic ovary syndrome: an experimental study. Int. J. Reprod. Biomed. 16, 149-158. doi: 10.29252/ijrm.16.3.149

Giachini, F. R., Galaviz-Hernandez, C., Damiano, A. E., Viana, M., Cadavid, A., Asturizaga, P., et al. (2017). Vascular dysfunction in mother and offspring during preeclampsia: contributions from latin-american countries. Curr. Hypertens. Rep. 19:83. doi: 10.1007/s11906-017-0781-7

Goulopoulou, S., and Davidge, S. T. (2015). Molecular mechanisms of maternal vascular dysfunction in preeclampsia. Trends Mol. Med. 21, 88-97. doi: 10.1016/ j.molmed.2014.11.009

Guilloty, N. I., Soto, R., Anzalota, L., Rosario, Z., Cordero, J. F., and Palacios, C. (2015). Diet. Pre-pregnancy BMI, and gestational weight gain in puerto rican women. Matern. Child Health J. 19, 2453-2461. doi: 10.1007/s10995-0151764-4

Han, L., Wang, H., Li, L., Li, X., Ge, J., Reiter, R. J., et al. (2017). Melatonin protects against maternal obesity-associated oxidative stress and meiotic defects 
in oocytes via the SIRT3-SOD2-dependent pathway. J. Pineal Res. 63:e12431. doi: $10.1111 /$ jpi.12431

Hansen, J. M., and Harris, C. (2013). Redox control of teratogenesis. Reprod. Toxicol. 35, 165-179. doi: 10.1016/j.reprotox.2012.09.004

Hastie, R., and Lappas, M. (2014). The effect of pre-existing maternal obesity and diabetes on placental mitochondrial content and electron transport chain activity. Placenta 35, 673-683. doi: 10.1016/j.placenta.2014. 06.368

Heslehurst, N., Ells, L. J., Simpson, H., Batterham, A., Wilkinson, J., and Summerbell, C. D. (2007). Trends in maternal obesity incidence rates, demographic predictors, and health inequalities in 36,821 women over a 15year period. BJOG 114, 187-194. doi: 10.1111/j.1471-0528.2006.01199.x

Hod, T., Cerdeira, A. S., and Karumanchi, S. A. (2015). Molecular mechanisms of Preeclampsia. Cold Spring Harb Perspect. Med. 5:a023473. doi: 10.1101/ cshperspect.a023473

Hung, T. H., Skepper, J. N., Charnock-Jones, D. S., and Burton, G. J. (2002). Hypoxia-reoxygenation: a potent inducer of apoptotic changes in the human placenta and possible etiological factor in preeclampsia. Circ. Res. 90, 12741281. doi: 10.1161/01.RES.0000024411.22110.AA

Igosheva, N., Abramov, A. Y., Poston, L., Eckert, J. J., Fleming, T. P., Duchen, M. R., et al. (2010). Maternal diet-induced obesity alters mitochondrial activity and redox status in mouse oocytes and zygotes. PLoS One 5:e10074. doi: 10.1371/ journal.pone. 0010074

Ishii, T., Miyazawa, M., Takanashi, Y., Tanigawa, M., Yasuda, K., Onouchi, H., et al. (2014). Genetically induced oxidative stress in mice causes thrombocytosis, splenomegaly and placental angiodysplasia that leads to recurrent abortion. Redox Biol. 2, 679-685. doi: 10.1016/j.redox.2014. 05.001

Jauniaux, E., Watson, A. L., Hempstock, J., Bao, Y. P., Skepper, J. N., and Burton, G. J. (2000). Onset of maternal arterial blood flow and placental oxidative stress. A possible factor in human early pregnancy failure. Am. J. Pathol. 157, 2111-2122. doi: 10.1016/S0002-9440(10)64849-3

Jia, Z., Feng, Z., Wang, L., Li, H., Wang, H., Xu, D., et al. (2018). Resveratrol reverses the adverse effects of a diet-induced obese murine model on oocyte quality and zona pellucida softening. Food Funct. 9, 2623-2633. doi: 10.1039/ c8fo00149a

Jones, D. P., Go, Y. M., Anderson, C. L., Ziegler, T. R., Kinkade, J. M. Jr., et al. (2004). Cysteine/cystine couple is a newly recognized node in the circuitry for biologic redox signaling and control. FASEB J. 18, 1246-1248. doi: 10.1096/fj. 03-0971fje

Kort, J. D., Winget, C., Kim, S. H., and Lathi, R. B. (2014). A retrospective cohort study to evaluate the impact of meaningful weight loss on fertility outcomes in an overweight population with infertility. Fertil. Steril. 101, 1400-1403. doi: 10.1016/j.fertnstert.2014.01.036

Lim, J., Nakamura, B. N., Mohar, I., Kavanagh, T. J., and Luderer, U. (2015). Glutamate cysteine ligase modifier subunit (Gclm) null mice have increased ovarian oxidative stress and accelerated age-related ovarian failure. Endocrinology 156, 3329-3343. doi: 10.1210/en.2015-1206

Longini, M., Perrone, S., Kenanidis, A., Vezzosi, P., Marzocchi, B., Petraglia, F., et al. (2005). Isoprostanes in amniotic fluid: a predictive marker for fetal growth restriction in pregnancy. Free Radic. Biol. Med. 38, 1537-1541. doi: 10.1016/j. freeradbiomed.2005.02.017

Lucas, E. S., Dyer, N. P., Murakami, K., Lee, Y. H., Chan, Y. W., Grimaldi, G., et al. (2016). Loss of endometrial plasticity in recurrent pregnancy loss. Stem Cells 34, 346-356. doi: 10.1002/stem.2222

Maged, A. M., Elsawah, H., Abdelhafez, A., Bakry, A., and Mostafa, W. A. (2015). The adjuvant effect of metformin and $\mathrm{N}$-acetylcysteine to clomiphene citrate in induction of ovulation in patients with polycystic ovary syndrome. Gynecol. Endocrinol. 31, 635-638. doi: 10.3109/09513590.2015.1 037269

Malti, N., Merzouk, H., Merzouk, S. A., Loukidi, B., Karaouzene, N., Malti, A., et al. (2014). Oxidative stress and maternal obesity: feto-placental unit interaction. Placenta 35, 411-416. doi: 10.1016/j.placenta.2014.03.010

Marchi, J., Berg, M., Dencker, A., Olander, E. K., and Begley, C. (2015). Risks associated with obesity in pregnancy, for the mother and baby: a systematic review of reviews. Obes. Rev. 16, 621-638. doi: 10.1111/obr. 12288
Matsuda, M., and Shimomura, I. (2013). Increased oxidative stress in obesity: implications for metabolic syndrome, diabetes, hypertension, dyslipidemia, atherosclerosis, and cancer. Obes. Res. Clin. Pract. 7, e330-e341. doi: 10.1016/j. orcp.2013.05.004

Mc Donald, A., Bradshaw, R. A., Fontes, F., Mendoza, E. A., Motta, J. A., Cumbrera, A., et al. (2015). Prevalence of obesity in panama: some risk factors and associated diseases. BMC Public Health 15:1075. doi: 10.1186/s12889-0152397-7

McCarthy, C., and Kenny, L. C. (2016). Therapeutically targeting mitochondrial redox signalling alleviates endothelial dysfunction in preeclampsia. Sci. Rep. 6:32683. doi: 10.1038/srep32683

Menting, M. D., van de Beek, C., de Rooij, S. R., Painter, R. C., Vrijkotte, T. G. M., and Roseboom, T. J. (2018). The association between prepregnancy overweight/obesity and offspring's behavioral problems and executive functioning. Early. Hum. Dev. 122, 32-41. doi: 10.1016/j.earlhumdev. 2018.05.009

Mert, I., Oruc, A. S., Yuksel, S., Cakar, E. S., Buyukkagnici, U., Karaer, A., et al. (2012). Role of oxidative stress in preeclampsia and intrauterine growth restriction. J. Obstet. Gynaecol. Res. 38, 658-664. doi: 10.1111/j.1447-0756.2011. 01771.x

Metwally, M., Ong, K. J., Ledger, W. L., and Li, T. C. (2008). Does high body mass index increase the risk of miscarriage after spontaneous and assisted conception? A meta-analysis of the evidence. Fertil. Steril. 90, 714-726. doi: 10.1016/j.fertnstert.2007.07.1290

Milne, F., Redman, C., Walker, J., Baker, P., Black, R., Blincowe, J., et al. (2009). Assessing the onset of pre-eclampsia in the hospital day unit: summary of the pre-eclampsia guideline (PRECOG II). BMJ 339:b3129. doi: 10.1136/bmj.b3129

Miller, H., Wilson, R., Jenkins, C., MacLean, M. A., Roberts, J., and Walker, J. J. (2000). Glutathione levels and miscarriage. Fertil. Steril. 74, 1257-1258. doi: 10.1016/S0015-0282(00) 01585-5

Mongraw-Chaffin, M. L., Cirillo, P. M., and Cohn, B. A. (2010). Preeclampsia and cardiovascular disease death: prospective evidence from the child health and development studies cohort. Hypertension 56, 166-171. doi: 10.1161/ HYPERTENSIONAHA.110.150078

Most, J., Marlatt, K. L., Altazan, A. D., and Redman, L. M. (2018). Advances in assessing body composition during pregnancy. Eur. J. Clin. Nutr. 72, 645-656. doi: 10.1038/s41430-018-0152-8

Murakami, K., Bhandari, H., Lucas, E. S., Takeda, S., Gargett, C. E., Quenby, S., et al. (2013). Deficiency in clonogenic endometrial mesenchymal stem cells in obese women with reproductive failure-a pilot study. PLoS One 8:e82582. doi: 10.1371/journal.pone.0082582

Nakamura, B. N., Fielder, T. J., Hoang, Y. D., Lim, J., McConnachie, L. A., Kavanagh, T. J., et al. (2011). Lack of maternal glutamate cysteine ligase modifier subunit $(\mathrm{Gclm})$ decreases oocyte glutathione concentrations and disrupts preimplantation development in mice. Endocrinology 152, 2806-2815. doi: 10.1210/en.2011-0207

Nasr, A. (2010). Effect of $\mathrm{N}$-acetyl-cysteine after ovarian drilling in clomiphene citrate-resistant PCOS women: a pilot study. Reprod. Biomed. Online 20, 403409. doi: 10.1016/j.rbmo.2009.12.012

NCD Risk Factor Collaboration (2016). Trends in adult body-mass index in 200 countries from 1975 to 2014: a pooled analysis of 1698 population-based measurement studies with 19.2 million participants. Lancet 387, 1377-1396. doi: 10.1016/S0140-6736(16) 30054-X

Negro, S., Boutsikou, T., Briana, D. D., Tataranno, M. L., Longini, M., Proietti, F., et al. (2017). Maternal obesity and perinatal oxidative stress: the strength of the association. J. Biol. Regul. Homeost. Agents 31, 221-227.

Nelson, S. M., Matthews, P., and Poston, L. (2010). Maternal metabolism and obesity: modifiable determinants of pregnancy outcome. Hum. Reprod. Update 16, 255-275. doi: 10.1093/humupd/dmp050

Ng, M., Fleming, T., Robinson, M., Thomson, B., Graetz, N., Margono, C., et al. (2014). Global, regional, and national prevalence of overweight and obesity in children and adults during 19802013: a systematic analysis for the global burden of disease study 2013. Lancet $384, \quad 766-781$. doi: $10.1016 /$ S0140-6736(14)60 460-8 
Nguyen, N. T., Magno, C. P., Lane, K. T., Hinojosa, M. W., and Lane, J. S. (2008). Association of hypertension, diabetes, dyslipidemia, and metabolic syndrome with obesity: findings from the national health and nutrition examination survey, 1999 to 2004. J. Am. Coll. Surg. 207, 928-934. doi: 10.1016/j.jamcollsurg. 2008.08.022

Pace, N. D., Desrosiers, T. A., Carmichael, S. L., Shaw, G. M., Olshan, A. F., SiegaRiz, A. M., et al. (2018). Antioxidant consumption is associated with decreased odds of congenital limb deficiencies. Paediatr. Perinat. Epidemiol. 32, 90-99. doi: $10.1111 /$ ppe. 12403

Persson, M., Cnattingius, S., Villamor, E., Soderling, J., Pasternak, B., Stephansson, O., et al. (2017). Risk of major congenital malformations in relation to maternal overweight and obesity severity: cohort study of 1.2 million singletons. BMJ 357:j2563. doi: 10.1136/bmj.j2563

Plagemann, A., and Harder, T. (2011). Fuel-mediated teratogenesis and breastfeeding. Diabetes Care 34, 779-781. doi: 10.2337/dc10-2369

Poston, L., Caleyachetty, R., Cnattingius, S., Corvalan, C., Uauy, R., Herring, S., et al. (2016). Preconceptional and maternal obesity: epidemiology and health consequences. Lancet Diabetes Endocrinol. 4, 1025-1036. doi: 10.1016/S22138587(16)30217-0

Quenby, S., Nik, H., Innes, B., Lash, G., Turner, M., Drury, J., et al. (2009). Uterine natural killer cells and angiogenesis in recurrent reproductive failure. Hum. Reprod. 24, 45-54. doi: 10.1093/humrep/den348

Radulescu, L., Munteanu, O., Popa, F., and Cirstoiu, M. (2013). The implications and consequences of maternal obesity on fetal intrauterine growth restriction. J. Med. Life 6, 292-298.

Rajasingam, D., Seed, P. T., Briley, A. L., Shennan, A. H., and Poston, L. (2009). A prospective study of pregnancy outcome and biomarkers of oxidative stress in nulliparous obese women. Am. J. Obstet. Gynecol. 395, e391-e399. doi: 10. 1016/j.ajog.2008.10.047

Rasmussen, S. A., Chu, S. Y., Kim, S. Y., Schmid, C. H., and Lau, J. (2008). Maternal obesity and risk of neural tube defects: a metaanalysis. Am. J. Obstet. Gynecol. 198, 611-619. doi: 10.1016/j.ajog.2008.04.021

Ray, P. D., Huang, B. W., and Tsuji, Y. (2012). Reactive oxygen species (ROS) homeostasis and redox regulation in cellular signaling. Cell. Signal. 24, 981-990. doi: 10.1016/j.cellsig.2012.01.008

Redman, C. W., and Sargent, I. L. (2000). Placental debris, oxidative stress and pre-eclampsia. Placenta 21, 597-602. doi: 10.1053/plac.2000.0560

Redman, C. W., and Sargent, I. L. (2005). Latest advances in understanding preeclampsia. Science 308, 1592-1594. doi: 10.1126/science.1111726

Roberts, J. M., and Escudero, C. (2012). The placenta in preeclampsia. Pregnancy Hypertens. 2, 72-83. doi: 10.1016/j.preghy.2012. 01.001

Roberts, J. M., Myatt, L., Spong, C. Y., Thom, E. A., Hauth, J. C., Leveno, K. J., et al. (2010). Vitamins C and E to prevent complications of pregnancy-associated hypertension. N. Engl. J. Med. 362, 1282-1291. doi: 10.1056/NEJMoa0908056

Roes, E. M., Raijmakers, M. T., Boo, T. M., Zusterzeel, P. L., Merkus, H. M., Peters, W. H., et al. (2006). Oral N-acetylcysteine administration does not stabilise the process of established severe preeclampsia. Eur. J. Obstet. Gynecol. Reprod. Biol. 127, 61-67. doi: 10.1016/j.ejogrb.2005. 09.007

Rosario, F. J., Kanai, Y., Powell, T. L., and Jansson, T. (2015). Increased placental nutrient transport in a novel mouse model of maternal obesity with fetal overgrowth. Obesity 23, 1663-1670. doi: 10.1002/oby.21165

Rumbold, A., Duley, L., Crowther, C. A., and Haslam, R. R. (2008). Antioxidants for preventing pre-eclampsia. Cochrane Database Syst. Rev. 1:CD004227. doi: 10.1002/14651858.CD004227. pub3

Rumbold, A., Ota, E., Hori, H., Miyazaki, C., and Crowther, C. A. (2015). Vitamin E supplementation in pregnancy. Cochrane Database Syst. Rev. 9:CD004069. doi: 10.1002/14651858.CD004069.pub3

Saker, M., Soulimane Mokhtari, N., Merzouk, S. A., Merzouk, H., Belarbi, B., and Narce, M. (2008). Oxidant and antioxidant status in mothers and their newborns according to birthweight. Eur. J. Obstet. Gynecol. Reprod. Biol. 141, 95-99. doi: 10.1016/j.ejogrb.2008.07.013

Salcedo-Bellido, I., Martinez-Galiano, J. M., Olmedo-Requena, R., Mozas-Moreno, J., Bueno-Cavanillas, A., Jimenez-Moleon, J. J., et al. (2017). Association between vitamin intake during pregnancy and risk of small for gestational age. Nutrients 9:E1277. doi: 10.3390/nu 9121277

Savini, I., Catani, M. V., Evangelista, D., Gasperi, V., and Avigliano, L. (2013). Obesity-associated oxidative stress: strategies finalized to improve redox state. Int. J. Mol. Sci. 14, 10497-10538. doi: 10.3390/ijms1405 10497

Schaefer-Graf, U., Napoli, A., Nolan, C. J., and Diabetic Pregnancy Study Group (2018). Diabetes in pregnancy: a new decade of challenges ahead. Diabetologia 61, 1012-1021. doi: 10.1007/s00125-018-4545-y

Showell, M. G., Mackenzie-Proctor, R., Jordan, V., and Hart, R. J. (2017). Antioxidants for female subfertility. Cochrane Database. Syst. Rev. 7:CD007807. doi: 10.1002/14651858.CD007807.pub3

Silvestris, E., de Pergola, G., Rosania, R., and Loverro, G. (2018). Obesity as disruptor of the female fertility. Reprod. Biol. Endocrinol. 16:22. doi: 10.1186/ s12958-018-0336-z

Sim, K. A., Partridge, S. R., and Sainsbury, A. (2014). Does weight loss in overweight or obese women improve fertility treatment outcomes? A systematic review. Obes. Rev. 15, 839-850. doi: 10.1111/obr.12217

Sliwa, K., and Bohm, M. (2014). Incidence and prevalence of pregnancy-related heart disease. Cardiovasc. Res. 101, 554-560. doi: 10.1093/cvr/cvu012

Srinivas, S. K., Edlow, A. G., Neff, P. M., Sammel, M. D., Andrela, C. M., and Elovitz, M. A. (2009). Rethinking IUGR in preeclampsia: dependent or independent of maternal hypertension? J. Perinatol. 29, 680-684. doi: 10.1038/ jp.2009.83

Steegers, E. A., von Dadelszen, P., Duvekot, J. J., and Pijnenborg, R. (2010). Pre-eclampsia. Lancet 376, 631-644. doi: 10.1016/S0140-6736(10)60279-6

Stothard, K. J., Tennant, P. W., Bell, R., and Rankin, J. (2009). Maternal overweight and obesity and the risk of congenital anomalies: a systematic review and meta-analysis. JAMA 301, 636-650.doi: 10.1001/jama.200 9.113

Tannetta, D. S., Dragovic, R. A., Gardiner, C., Redman, C. W., and Sargent, I. L. (2013). Characterisation of syncytiotrophoblast vesicles in normal pregnancy and pre-eclampsia: expression of Flt1 and endoglin. PLoS One 8:e56754. doi: 10.1371/journal.pone.00 56754

van der Steeg, J. W., Steures, P., Eijkemans, M. J., Habbema, J. D., Hompes, P. G., Burggraaff, J. M., et al. (2008). Obesity affects spontaneous pregnancy chances in subfertile, ovulatory women. Hum. Reprod. 23, 324-328. doi: 10.1093/humrep/ $\operatorname{dem} 371$

Viana, M., Herrera, E., and Bonet, B. (1996). Teratogenic effects of diabetes mellitus in the rat. Prevention by vitamin E. Diabetologia 39, 1041-1046. doi: 10.1007/ BF00400652

Villar, J., Carroli, G., Wojdyla, D., Abalos, E., Giordano, D., Ba'aqeel, H., et al. (2006). Preeclampsia, gestational hypertension and intrauterine growth restriction, related or independent conditions? Am. J. Obstet. Gynecol. 194, 921-931. doi: 10.1016/j.ajog.2005.10.813

Wang, H., Cheng, Q., Li, X., Hu, F., Han, L., Zhang, H., et al. (2018). Loss of TIGAR induces oxidative stress and meiotic defects in oocytes from obese mice. Mol. Cell. Proteomics 17, 1354-1364. doi: 10.1074/mcp.RA118. 000620

Wang, X. D., Morgan, S. C., and Loeken, M. R. (2011). Pax3 stimulates p53 ubiquitination and degradation independent of transcription. PLoS One 6:e29379. doi: 10.1371/journal.pone.0029379

Wells, P. G., McCallum, G. P., Lam, K. C., Henderson, J. T., and Ondovcik, S. L. (2010). Oxidative DNA damage and repair in teratogenesis and neurodevelopmental deficits. Birth Defects Res. C Embryo Today 90, 103-109. doi: 10.1002/bdrc.20177

Wise, L. A., Rothman, K. J., Mikkelsen, E. M., Sorensen, H. T., Riis, A., and Hatch, E. E. (2010). An internet-based prospective study of body size and time-to-pregnancy. Hum. Reprod. 25, 253-264. doi: 10.1093/humrep/ $\operatorname{dep} 360$

Wu, F., Tian, F. J., and Lin, Y. (2015). Oxidative stress in placenta: health and diseases. Biomed. Res. Int. 2015:293271. doi: 10.1155/2015/293271

Wu, Y., Viana, M., Thirumangalathu, S., and Loeken, M. R. (2012). AMP-activated protein kinase mediates effects of oxidative stress on embryo gene expression in a mouse model of diabetic embryopathy. Diabetologia 55, 245-254. doi: 10.1007/s00125-011-2326-y 
Yao, R., Park, B. Y., and Caughey, A. B. (2017). The effects of maternal obesity on perinatal outcomes among those born small for gestational age. J. Matern. Fetal Neonatal Med. 30, 1417-1422. doi: 10.1080/14767058.2016.121 6098

Yiyenoglu, O. B., Ugur, M. G., Ozcan, H. C., Can, G., Ozturk, E., Balat, O., et al. (2014). Assessment of oxidative stress markers in recurrent pregnancy loss: a prospective study. Arch. Gynecol. Obstet. 289, 1337-1340. doi: 10.1007/s00404013-3113-4

Yu, Z., Han, S., Zhu, J., Sun, X., Ji, C., and Guo, X. (2013). Pre-pregnancy body mass index in relation to infant birth weight and offspring overweight/obesity: a systematic review and meta-analysis. PLoS One 8:e61627. doi: 10.1371/journal. pone.0061627

Zadrozna, M., Gawlik, M., Nowak, B., Marcinek, A., Mrowiec, H., Walas, S., et al. (2009). Antioxidants activities and concentration of selenium, zinc and copper in preterm and IUGR human placentas. J. Trace Elem. Med. Biol. 23, 144-148. doi: 10.1016/j.jtemb.2009.02.005

Conflict of Interest Statement: The authors declare that the research was conducted in the absence of any commercial or financial relationships that could be construed as a potential conflict of interest.

Copyright (C) 2018 Alcala, Gutierrez-Vega, Castro, Guzman-Gutiérrez, RamosAlvarez and Viana. This is an open-access article distributed under the terms of the Creative Commons Attribution License (CC BY). The use, distribution or reproduction in other forums is permitted, provided the original author(s) and the copyright owner(s) are credited and that the original publication in this journal is cited, in accordance with accepted academic practice. No use, distribution or reproduction is permitted which does not comply with these terms. 